\title{
Greater use of insulin by southern European compared with Anglo-Celt patients with type 2 diabetes: the Fremantle Diabetes Study
}

\author{
Rhonda M Clifford ${ }^{1,2}$, Wendy A Davis ${ }^{1}$, Carole A Cull ${ }^{3}$, David G Bruce ${ }^{1}$, Kevin T Batty ${ }^{2}$ and Timothy M E Davis ${ }^{1}$ \\ ${ }^{1}$ School of Medicine and Pharmacology, University of Western Australia, Fremantle Hospital, PO Box 480, Fremantle, Western Australia 6959, \\ Australia, ${ }^{2}$ School of Pharmacy, Curtin University, Bentley, Western Australia, Australia and ${ }^{3}$ Diabetes Trials Unit, Oxford Centre for Diabetes \\ Endocrinology and Metabolism, University of Oxford, Oxford, UK
}

(Correspondence should be addressed to T M E Davis; Email: tdavis@cyllene.uwa.edu.au)

\begin{abstract}
Objective: To investigate the relationship between blood glucose-lowering therapy, glycaemia and ethnicity in urban Australians with type 2 diabetes.

Design: Prospective observational community-based study of diabetes care, control and complications. Methods: We analysed cross-sectional data from 1057 patients, 238 from a southern European (SE) migrant background and 819 Anglo-Celts (AC). Follow-up data were available for 539 patients (113 SE, 426 AC) who had annual reviews over 4 years.

Results: The SE patients were of similar age to the AC patients but had longer diabetes duration, were less fluent in English and had less formal education. After adjustment for diabetes duration, glycosylated haemoglobin and glutamic acid decarboxylase antibody positivity in a logistic regression model, insulin use at study entry was approximately twice as frequent amongst SE as AC patients (odds ratio $(95 \%$ confidence interval); $1.90(1.20-3.02)$ ). In the prospective arm, progression to insulin increased in both groups, from $18.0 \%$ at baseline to $22.1 \%$ at 4 years in SE and from $7.1 \%$ to $14.4 \%$ in $\mathrm{AC}$ patients. $\beta$-cell function $(\% \mathrm{~B})$ and insulin sensitivity $(\% \mathrm{~S})$ using the homoeostasis model assessment in a subset of diet-treated patients at baseline showed that SE ethnicity was associated with lower $\% \mathrm{~B}$ and greater $\% \mathrm{~S}$ than in the $\mathrm{AC}$ group.

Conclusions: SE patients with early non-antibody-mediated $\beta$-cell failure progress to insulin requirement within the first $4-5$ years of type 2 diabetes. This could reflect either a longer period of undiagnosed diabetes or a more rapid loss of $\beta$-cell function after diagnosis.
\end{abstract}

European Journal of Endocrinology 151 579-586

\section{Introduction}

Recent Australian history has seen a significant influx of migrants, especially from Europe after World War 2. In 1989-90, the Australian National Health Survey reported a greater prevalence of diabetes among all major groups of immigrants compared with Australian-born adults (1). The highest overall prevalence was for those of southern European (SE) ethnicity, with SE males and females having more than double the prevalence in the Australian-born, principally Anglo-Celt (AC), population (2). Given cultural, linguistic and economic barriers, it is not surprising that Australian minority groups need special programmes that cover aspects of diabetes care including education (3) and management of complications (4). There is, however, a paucity of data that allow an assessment of glycaemic control in Australian migrants with type 2 diabetes.
The Fremantle Diabetes Study (FDS), which was conducted between 1993 and 2001, recruited 1294 patients with type 2 diabetes to a prospective, observational study $(5,6)$. Of these, the largest non-AC group was of SE ethnic background $(18.4 \%$ of the FDS cohort). Based on Australian Bureau of Statistics census data for the overall percentage of SE individuals living in the FDS catchment area of 120097 people $(6 \%)(7)$, the SE patients were threefold over-represented in the FDS. This finding is consistent with contemporaneous national survey data $(1,2)$ and, together with other data confirming its representative nature $(5,6)$, suggests that the FDS sample can be used to investigate ethnic aspects of type 2 diabetes in an urban Australian setting. We have, therefore, assessed the relationship between glycaemic control, blood glucose-lowering therapies and ethnicity in type 2 SE and AC patients from the FDS. 


\section{Subjects and methods}

\section{Subjects}

The FDS was a prospective observational study of patients from a postcode-defined area surrounding the port of Fremantle in Western Australia. We studied $1057(81.9 \%)$ of the 1294 type 2 patients from the community-based FDS cohort who were of either SE or AC ethnic background. The FDS protocol was approved by the Human Rights Committee, Fremantle Hospital and all patients gave informed consent to participation. A description of recruitment strategies, characteristics of the sample including diabetes type, and details of identified but unrecruited patients have been published elsewhere $(5,6)$.

\section{Methods}

All patients were recruited and had a baseline assessment between 1993 and 1996, and were asked to attend for further annual comprehensive assessments thereafter. At their first and subsequent annual visits, a comprehensive history was taken and a physical examination was performed (5). Detailed demographic and socioeconomic data were recorded in addition to details of all medical conditions including diabetes. Patients were requested to bring all medications to each visit and details, including doses, were recorded. Any missing medication data were collected through follow-up telephone calls and/or review of hospital case notes. Compliance with therapy was assessed from self-report. Each patient provided fasting blood and urine samples for automated biochemical analyses (5). Antibodies to glutamic acid decarboxylase (GAD) were assayed as described previously $(8,9)$.

Ethnic background was assessed largely from selfselection of one of six categories: (i) northern European (principally AC), (ii) SE, (iii) Asian, (iv) African, (v) aboriginal/Torres Strait islander and (vi) other (including mixed ethnicity). Supplementary criteria used for ethnic background included country of birth, country of father's/mother's birth and language spoken at home. Of the 1294 patients with type 2 diabetes identified in the 3-year registration period, 819 (63\%) were of AC and $238(18 \%)$ of SE ethnic background. The former patients had family origins in the United Kingdom and Ireland. In the SE group, 210 of the 238 (88\%) had been born outside Australia and had lived in Australia for an average of 35 (range 2-63) years. Of these, most (156 or $74 \%$ ) were born in Italy with the majority of the remainder born in Portugal, Spain or Greece. Of the 28 SE patients born in Australia, 21 $(75 \%)$ reported that both parents were born in Italy.

Retinopathy (at least one microaneurysm in either eye or worse) was assessed from direct and/or indirect ophthalmoscopy through dilated pupils, and/or more detailed ophthalmological data in patients assessed for photocoagulation. Neuropathy was defined as a score of $>2 / 8$ using the Michigan Neuropathy Screening Instrument clinical portion (10). Nephropathy was defined as an urine albumin:urine creatinine ratio $(\mathrm{ACR}) \geq 3.0 \mathrm{mg} / \mathrm{mmol}$.

\section{Data analysis}

$\beta$-cell function (\%B) and insulin sensitivity (\%S) were estimated from fasting serum glucose and insulin concentrations using the homeostasis model assessment (HOMA) (11). Statistical analysis was performed using SPSS for Windows (version 11.5; SPSS Inc, Chicago, IL, USA) and SAS for Windows (version 8.2; SAS Institute Inc., Cary, NC, USA). Data are reported as means \pm S.D., geometric mean (s.D. range), median [interquartile range] or percentage. Two-sample comparisons for normally distributed variables were by Student's $t$-test. Comparisons of proportions were by chi-square tests. The Cochran-Armitage test for trend was used to compare proportions across ordinal categories. Cochran's Q test was used to assess repeated measures of dichotomous variables.

A logistic regression model was used to assess the factors associated with therapy at recruitment to the study. Time to requirement for insulin following recruitment in those patients not taking insulin at recruitment was assessed using a Kaplan-Meier survival model. Survival curves defined by ethnic group were constructed and compared with the log-rank test. Cox proportional hazards modelling was used to determine whether ethnic group was an independent predictor of future insulin use after adjustment for potential confounding variables. The validity of the proportional hazards assumption was assessed from $\log (-\log ($ survival $))$ curves and examination of timedependent covariates. A level of $P<0.05$ was taken as significant throughout.

\section{Results}

\section{Baseline patient characteristics}

Details of the 238 SE and 819 AC patients at study entry are summarised in Table 1. The SE patients were of similar age to the AC patients but had significantly longer duration of diabetes and were, therefore, younger at diagnosis. The SE patients were less likely to speak English fluently and to have had education beyond primary school level. The SE patients had a greater body mass index (BMI) than the AC group but waist circumference and waist:hip ratio were similar. Fasting serum glucose and glycosylated haemoglobin $\left(\mathrm{HbA}_{1 \mathrm{c}}\right)$ were both significantly higher amongst SE patients at baseline. SE patients were approximately twice as likely as AC patients to be taking insulin, although median doses in the two groups were similar. Smoking habits, alcohol intake and exercise history were similar in the two groups. 
Table 1 Characteristics of SE and AC type 2 FDS patients at baseline for both cross-sectional $(n=1057)$ and prospective $(n=539)$ samples. Values are means \pm S.D. or medians and interquartile ranges shown in parentheses.

\begin{tabular}{|c|c|c|c|c|}
\hline & \multicolumn{2}{|c|}{ Cross-sectional study } & \multicolumn{2}{|c|}{ Prospective study } \\
\hline & SE & $A C$ & SE & $A C$ \\
\hline Number (\%) & 238 & 819 & 113 & 426 \\
\hline Male $(\%)$ & 45.4 & 49.5 & 51.3 & 51.9 \\
\hline Duration of diabetes at baseline (years) & $5.3[2.2-11.9]^{\star * *}$ & $4.1[1.0-8.3]$ & $4.0[1.0-10.5]^{*}$ & $3.0[0.8,6.9]$ \\
\hline Age at baseline (years) & $63.6 \pm 10.3$ & $64.8 \pm 11.3$ & $62.0 \pm 9.5$ & $63.3 \pm 9.3$ \\
\hline Age at diagnosis of diabetes (years) & $55.9 \pm 10.3^{\star * *}$ & $59.1 \pm 11.5$ & $55.2 \pm 10.0^{* *}$ & $58.5 \pm 10.1$ \\
\hline English fluency (\%) & $37.1^{\star \star *}$ & 100 & $42.5^{\star \star \star}$ & 100 \\
\hline Education beyond primary school (\%) & $32.8^{\star \star \star}$ & 85.4 & $32.7^{\star \star \star}$ & 87.0 \\
\hline Body mass index $\left(\mathrm{kg} / \mathrm{m}^{2}\right)$ & $30.3 \pm 4.7^{\star}$ & $29.6 \pm 5.6$ & $30.0 \pm 4.3$ & $29.5 \pm 5.5$ \\
\hline Waist:hip ratio & $0.91 \pm 0.06$ & $0.91 \pm 0.08$ & $0.91 \pm 0.07$ & $0.91 \pm 0.08$ \\
\hline GAD positive (\%) & 1.7 & 4.2 & 2.8 & 3.6 \\
\hline Fasting serum glucose (mmol/l) & $9.0[7.3-11.3]^{\star *}$ & $8.2[6.7-10.6]$ & $8.7[7.2-10.7]^{\star}$ & $8.1[6.7-10.3]$ \\
\hline $\mathrm{HbA}_{\mathrm{lc}}(\%)$ & $7.9[6.7-9.1]^{\star \star}$ & $7.3[6.3-8.7]$ & $7.6[6.3-8.8]$ & $7.1[6.3-8.3]$ \\
\hline \multicolumn{5}{|l|}{ Treatment } \\
\hline Diet $(\%)$ & $22.0 * \star *$ & 34.9 & $24.3^{*}$ & 37.2 \\
\hline Oral hypoglycaemic drugs (\%) & 58.5 & 54.8 & 57.7 & 55.8 \\
\hline Insulin (\%) & $19.5^{\star \star}$ & 10.3 & $18.0^{* *}$ & 7.1 \\
\hline Insulin dose (units/kg) & $0.55[0.41-0.76]$ & $0.53[0.47-0.69]$ & $0.55[0.41-0.69]$ & $0.56[0.45-0.69]$ \\
\hline Current smokers (\%) & 12.7 & 15.1 & 16.8 & 13.9 \\
\hline Any exercise in the last 2 weeks (\%) & 72.2 & 72.0 & 79.5 & 78.7 \\
\hline Alcohol consumption (standard drinks/day) & $0[0-1.2]$ & $0[0-0.4]$ & $0.1[0-1.2]$ & $0[0-0.8]$ \\
\hline Retinopathy (\%) & $26.1^{\star \star *}$ & 13.5 & $25.0^{* \star \star}$ & 10.0 \\
\hline Neuropathy (\%) & $25.4^{*}$ & 32.9 & 20.7 & 25.7 \\
\hline $\mathrm{ACR}>3.0 \mathrm{mg} / \mathrm{mmol}(\%)$ & $48.9^{*}$ & 40.1 & 44.0 & 34.7 \\
\hline
\end{tabular}

$\mathrm{HbA}_{\mathrm{Ic}}$, glycosylated haemoglobin.

${ }^{\star} P<0.05,{ }^{* \star} P<0.01,{ }^{* \star *} P<0.001$ vs AC patients.

The comparative prevalence of microvascular complications did not show a consistent pattern. The proportion with any manifestation of microangiopathy was greater amongst SE patients $(64.3 \%$ vs $56.7 \%$ in AC; $P=0.043)$.

\section{Determinants of blood glucose-lowering therapy at baseline}

We examined the contribution of likely determinants of insulin use in a logistic regression model. Age at recruitment, duration of diabetes, sex, ethnicity, GAD antibody positivity, BMI, fasting serum glucose and $\mathrm{HbA}_{1 \mathrm{c}}$ were included as independent variables in the model and use of insulin at study entry as the dependent variable (see Table 2). Longer duration, SE ethnicity, GAD antibody positivity and $\mathrm{HbA}_{1 \mathrm{c}}$ at recruitment were each significant and independent predictors of insulin self-administration. Insulin use remained more than twice as frequent amongst SE than AC patients after adjusting for the other variables.

Figure 1 shows the percentage of patients using different therapies for diabetes at recruitment according to ethnic group and $\mathrm{HbA}_{1 \mathrm{c}}$ categorised into approximate quartiles $<6.5 \%, 6.5 \%$ to $7.4 \%$, $7.5 \%$ to $8.4 \%$ and $\geq 8.5 \%$. At each interval of $\mathrm{HbA}_{1 \mathrm{c}}$ above $6.5 \%$, there was a greater percentage of insulin-treated SE patients $(P<0.01$ by test for trend). This was particularly evident at $\mathrm{HbA}_{1 \mathrm{c}}$ values $>8.5 \%$ (36.3\% vs $17.9 \%$ of SE and AC patients respectively) and persisted when
Table 2 Odds ratio (OR) and 95\% confidence intervals (Cl) for associates of insulin use at study entry by subjects in the crosssectional group $(n=1057)$. OR $(95 \% \mathrm{Cl})$ for significant variables are shown in bold.

\begin{tabular}{lc}
\hline Baseline variable & OR $(95 \% \mathrm{Cl})$ \\
\hline Age at study entry (years) & $0.99(0.97-1.02)$ \\
Duration of diabetes at study entry (years) & $\mathbf{1 . 1 6}(\mathbf{1 . 1 2 - 1 . 1 9 )}$ \\
Sex (female vs male) & $1.00(0.65-1.56)$ \\
Ethnicity $(\mathrm{SE}$ vs AC) & $\mathbf{1 . 9 0}(\mathbf{1 . 2 0 - 3 . 0 2 )}$ \\
BMI $\left(\mathrm{kg} / \mathrm{m}^{2}\right)$ & $0.99(0.95-1.03)$ \\
GAD antibody positivity & $7.84(3.57-17.2)$ \\
Fasting serum glucose (mmol/l) & $1.04(0.96-1.13)$ \\
$\mathrm{HbA}_{\mathrm{lc}}(\%)$ & $\mathbf{1 . 1 9}(\mathbf{1 . 0 3 - 1 . 3 9 )}$ \\
\hline
\end{tabular}

patients taking insulin were further subdivided into groups based on whether or not oral hypoglycaemic agents were also being taken (data not shown). There were fewer SE than AC patients on diet alone in each $\mathrm{HbA}_{1 \mathrm{c}}$ category.

\section{Relationship between ethnicity, blood glucose- lowering therapy and glycaemic control at baseline}

We assessed the relationship between the effectiveness of blood-glucose lowering therapy and ethnicity by comparing the $\mathrm{HbA}_{1 \mathrm{c}}$ levels of $\mathrm{SE}$ and $\mathrm{AC}$ patients on diet alone, oral hypoglycaemic medication, or insulin with or without oral hypoglycaemic therapy. There were no statistically significant differences in $\mathrm{HbA}_{1 \mathrm{c}}$ 

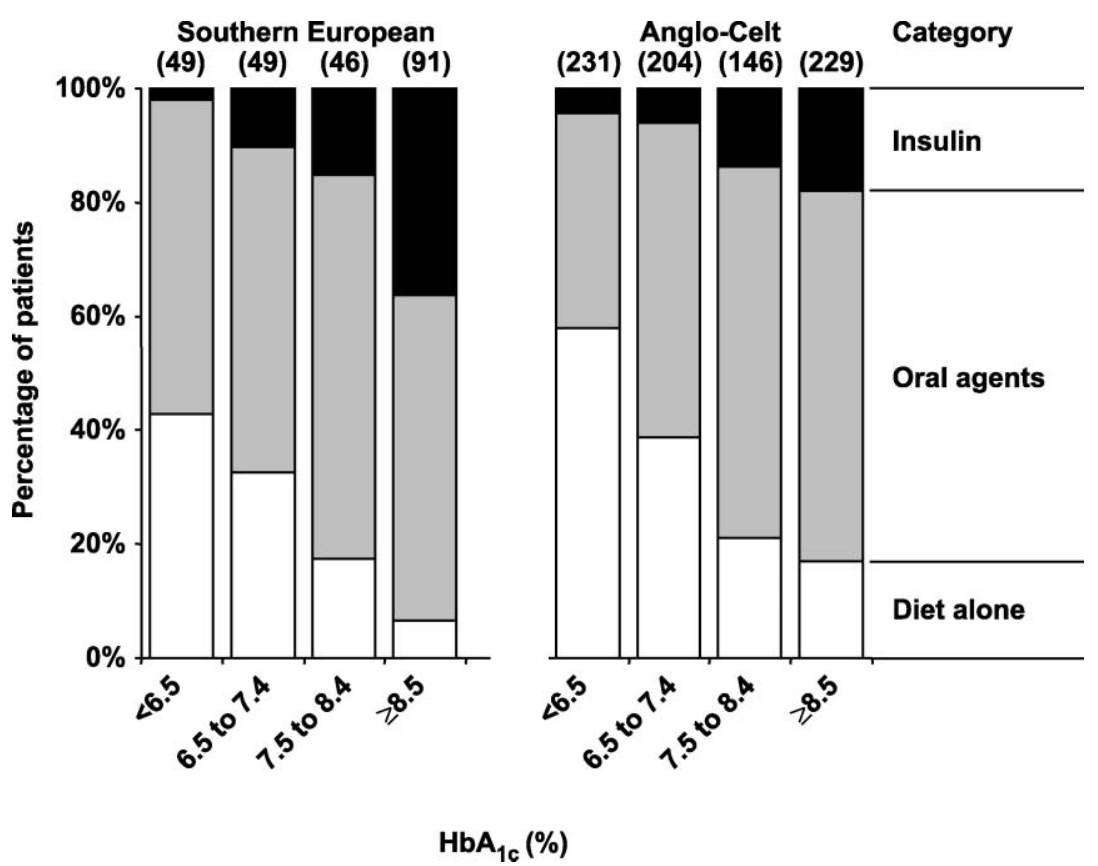

Figure 1 Bar graph showing the distribution of treatments for diabetes by ethnic group and $\mathrm{HbA}_{1 \mathrm{c}}$ category at entry into the FDS. Numbers of patients in each category are given in parentheses at the top of each bar.

by treatment modality and ethnic group $(P>0.09$; see Fig. 2).

Fasting serum insulin concentrations, and therefore HOMA estimates of $\% \mathrm{~B}$ and $\% \mathrm{~S}$, were available for an unselected sample of 307 of the 922 patients who were not taking insulin at baseline (33.3\%). These patients were older than those not selected (age $65.8 \pm 10.2$ vs $63.4 \pm 11.7$ years; $P=0.002$ ) but had a similar sex distribution, diabetes duration, fasting serum glucose, $\mathrm{HbA}_{1 \mathrm{c}}$ and distribution of blood glucose-lowering therapies $(P>0.1)$. As with $\mathrm{HbA}_{1 \mathrm{c}}$, we analysed these log-transformed data by type of treatment (see Fig. 3). In the case of diet-treated patients,

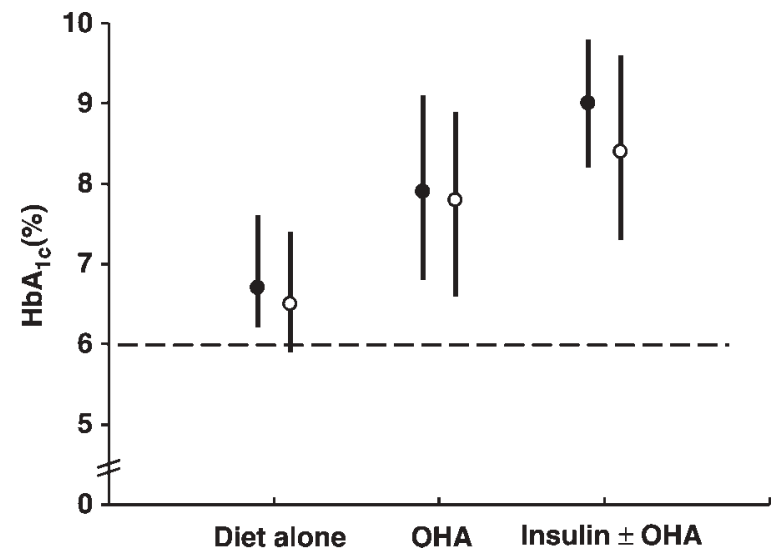

Figure 2 Median and interquartile range (vertical bars) for $\mathrm{HbA}_{1 \mathrm{c}}$ classified by treatment type and ethnic group (SE (•), AC (०)). The upper limit of the reference range for the assay $(6.0 \%)$ is shown as a horizontal hatched line. OHA, oral hypoglycaemic agents. there was a significantly lower \%B (31 (16-59) vs 58 $(30-113) \% ; P=0.002)$ and greater \% $(65(31-$ $138)$ vs $35(17-72) \% ; P=0.006)$ in the 12 SE compared with the $102 \mathrm{AC}$ patients, but no such differences were observed for the $30 \mathrm{SE}$ and $163 \mathrm{AC}$ patients on oral hypoglycaemic therapy $(P>0.17)$.

\section{Prospective data}

Longitudinal data from the 539 patients who attended four annual FDS review visits were analysed separately. Compared with the 518 SE or AC type 2 FDS patients who did not complete 4 years of follow-up, the subjects in this subgroup were younger at recruitment

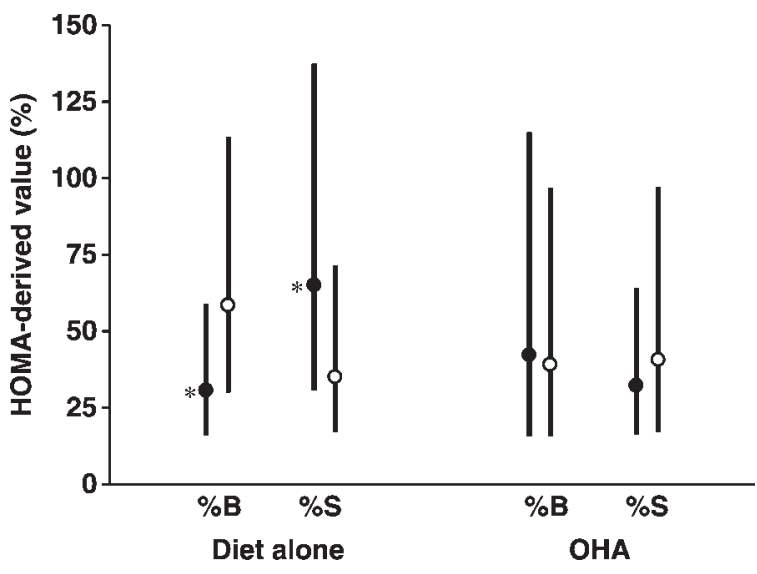

Figure 3 Geometric mean and S.D. range (vertical bars) for HOMA estimates of $\% B$ and $\% S$ by treatment type and ethnic group (SE $(\bullet)$, AC (०)). OHA, oral hypoglycaemic agents. 
(63.0 \pm 9.4 vs $66.1 \pm 12.4$ years; $P<0.001)$ and were more likely to be male ( 51.8 vs $45.2 \%$; $P=0.036)$. The patients in the prospective arm also had a shorter duration of diabetes $(3.3[0.8-7.3]$ vs 5.0 [1.5-10.0] years; $P<0.001)$, a lower fasting serum glucose $(8.2$ $[6.8-10.4]$ vs $8.7[6.9-11.2] \mathrm{mmol} / \mathrm{l} ; P=0.020)$ and lower $\mathrm{HbA}_{1 \mathrm{c}}(7.2[6.3-8.5]$ vs 7.7 [6.5-9.2] \%; $P<0.001)$.

The differences between the SE and AC patients included in the prospective arm were consistent with those seen in the larger cross-sectional sample (see Table 1). The SE patients were significantly younger at diagnosis of diabetes but of similar age and thus had a longer duration of diabetes at recruitment. Their fasting serum glucose was significantly higher but there were no significant differences in $\mathrm{HbA}_{1 \mathrm{c}}$ or measures of obesity. Insulin use at study entry was significantly more frequent amongst SE patients.

Median [interquartile range] $\mathrm{HbA}_{1 \mathrm{c}}$ levels in both ethnic groups over the 4 years of follow-up are shown in Fig. 4. After adjusting for age at recruitment, duration of diabetes and BMI there were no significant differences between ethnic groups in either the change in $\mathrm{HbA}_{1 \mathrm{c}}$ over the 4 years $(P=0.56)$ or in the updated mean $\operatorname{HbA}_{1 \mathrm{c}}(P=0.93)$. The distributions of treatment type by ethnic group over the 4 years of follow-up are shown in Fig. 5. There were increases in the use of insulin and oral hypoglycaemic agents in both groups over time. The SE patients in the prospective study remained more likely to be taking insulin (alone or in combination with oral hypoglycaemic agents) after 4 years of follow-up (22.1 vs $14.4 \% ; P=0.059)$. Time to requirement for insulin from study entry was assessed using a Kaplan-Meier survival model, but there was no difference between ethnic groups $(P=0.49$ by $\log$ rank test). After adjusting for age,

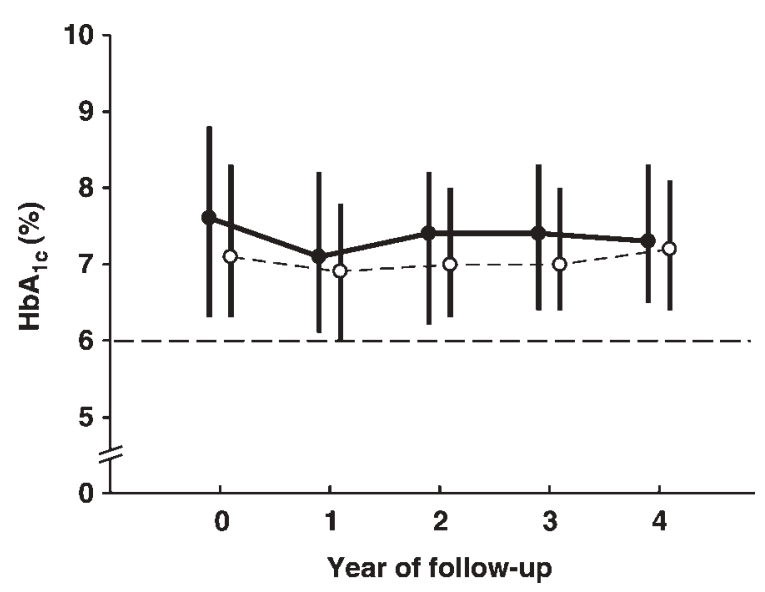

Figure 4 Median and interquartile range (vertical bars) for $\mathrm{HbA}_{1 \mathrm{c}}$ by assessment number $(0=$ baseline visit) and ethnic group (SE $(\bullet), A C(\circ))$. The upper limit of the reference range for the assay $(6.0 \%)$ is shown as a horizontal hatched line. gender, diabetes duration, BMI, GAD antibody positivity, fasting serum glucose and $\mathrm{HbA}_{1 \mathrm{c}}$ at study entry in a Cox proportional hazards model, ethnic group was not significantly associated with progression to insulin treatment $(P=0.56)$.

\section{Discussion}

We found that patients with type 2 diabetes from an SE ethnic background were approximately twice as likely to be self-administering insulin as type $2 \mathrm{AC}$ patients in the same community-based cohort drawn from an urban Australian setting. This difference was not explained by potentially confounding variables including duration of known diabetes, glycaemic control and GAD antibody status, and was most marked at relatively high $\mathrm{HbA}_{1 \mathrm{c}}$ levels $(>8.5 \%)$. In a subset of patients followed for 4 years, the trend to relatively greater use of insulin by SE patients persisted.

Most of our SE patients were first-generation migrants from Italy, Greece, Spain and Portugal. Just under one in five of them was taking insulin at entry into the FDS at a time when they had been diabetic for a median of 5 years. After a further 4 years of follow-up, $22.1 \%$ of the prospective subgroup was insulin treated. In studies from SE countries (12-16), insulin use in type 2 diabetes ranged from 9 to $23 \%$ for a duration of diabetes of approximately 10 years. Only one of these, a nationwide Italian study (15), provided $\mathrm{HbA}_{1 \mathrm{c}}$ data, with a mean $\mathrm{HbA}_{1 \mathrm{c}}$ of $7.3 \%$ in the $19.8 \%$ of type 2 patients who were on insulin. Taken together, these data suggest that insulin use amongst the SE patients in the FDS was at the upper limit of that in their countries of origin but that glycaemic control was less satisfactory. The majority of our SE patients neither spoke English fluently nor had received a formal education beyond primary school level. Although this suggests that most were still following a traditional lifestyle, it could be that a shift away from a Mediterranean diet contributed to the relatively poor glycaemic control and greater insulin use in our Australian-dwelling SE patients.

The progressive nature of type 2 diabetes (17), and the deleterious effects of both hyperglycaemia (18) and islet-specific antibodies on $\beta$-cell function, are reflected in the associations between insulin use in our patients and longer diabetes duration, higher $\mathrm{HbA}_{1 \mathrm{c}}$ levels and GAD antibody positivity. There were significant differences between SE and AC patients in each of these variables and so it was important to confirm that SE ethnicity was an independent determinant of insulin therapy. Self-reported adherence with medication for diabetes was similar in our SE and AC patients (data not shown) and $\mathrm{HbA}_{1 \mathrm{c}}$ levels were comparable in oral hypoglycaemic-treated patients in the two groups, suggesting that the ethnic differences in progression to insulin were not determined by compliance with therapy. 


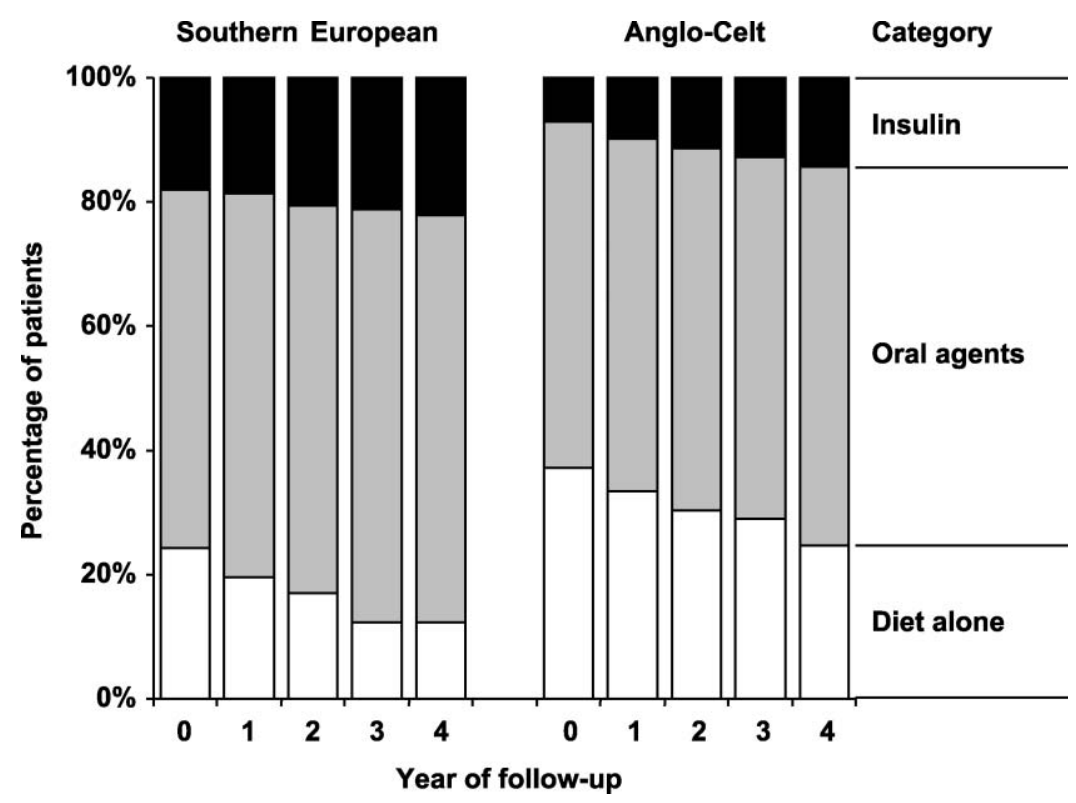

Figure 5 Bar graph showing the distribution of treatments for diabetes by ethnic group and year of follow-up $(0=$ baseline visit).

Socioeconomic variables such as income, English fluency and level of education were highly correlated with ethnicity in the present study, and so it was not possible to assess their independent influence on therapeutic modality. However, the Medicare system, introduced in 1984 and underpinned by a tax levy, provides universal comprehensive medical and hospital coverage for all Australians. In fact, in the 2 years prior to recruitment, SE patients made more visits to their general practitioners than AC $(6$ [2-12] vs 4 [1-8]; $P=0.012)$. It may be that an earlier introduction of insulin therapy is a consequence of greater concern about glycaemic control on the part of the SE patient and/or general practitioner than was the case in the AC group. Data from the USA show that African Americans with diabetes are more likely to be insulin treated than white Caucasian patients (19), but this is in the context of markedly different racial groups and health care systems, complicating comparisons with the present data.

We assessed HOMA-derived $\% \mathrm{~B}$ and $\% \mathrm{~S}$ as an indication of whether pathophysiological factors contributed to the present ethnic differences in insulin use. Although these data were derived from a subgroup, the patients were similar to those who were not included. It is of interest that, in subjects on diet alone, SE ethnicity was associated with a greater impairment of $\beta$-cell function. It is possible that the progressive loss of $\beta$-cell function that characterises type 2 diabetes (17) is relatively rapid in SE patients and that its effects are offset initially by greater insulin sensitivity. The differences in $\% \mathrm{~S}$ appeared independent of measures of body fat which were largely comparable in the two groups of subjects. It may be that other factors, including diet, influence $\% \mathrm{~S}$ and that maintenance of at least a partial traditional lifestyle is of benefit in our SE patients.

Estimates of $\% \mathrm{~B}$ and $\% \mathrm{~S}$ in patients receiving oral hypoglycaemic therapy, and thus at a later stage of diabetes, will be influenced by the effects of the drugs on endogenous insulin production and tissue insulin response and are more difficult to interpret as a result. Nevertheless, there were no differences in \%B and $\% \mathrm{~S}$ between the groups for this therapeutic modality and the rate at which patients progressed to insulin was similar in SE and AC patients, after adjustment for confounding variables, in the prospective arm of the study.

An alternative explanation for the relatively low $\% \mathrm{~B}$ in the diet-treated SE patients in particular and the greater use of insulin in the SE group as a whole is that they had undiagnosed diabetes for longer than $\mathrm{AC}$ subjects in the presence of the same rate of $\beta$-cell decline. This would fit with the greater prevalence of retinopathy in the SE group (20) especially since the older AC patients should be at greater risk of this complication (21). In addition, our SE patients were less often diagnosed incidentally (28.7 vs $42.7 \%$ in AC patients) than with hyperglycaemic symptoms (50.5 vs $40.4 \% ; P=0.003)$, suggesting a relatively late presentation. Given that the present group-specific prevalence data for sensory neuropathy and nephropathy do not support this hypothesis, there is a need for further longitudinal studies of ethnicity and the development of $\beta$-cell dysfunction and insulin insensitivity.

Our prospective median $\mathrm{HbA}_{1 \mathrm{c}}$ data showed an initial reduction between baseline and first review, presumably because the FDS patients were subject to monitoring that was additional to usual care. There was a rise thereafter despite an increase in number and amount of 
blood glucose-lowering therapies used, including insulin, in both ethnic groups. This situation parallels that in the United Kingdom Prospective Diabetes Study (UKPDS) (22). UKPDS data have shown that the majority of patients will require insulin to achieve an $\mathrm{HbA}_{1 \mathrm{c}}<7.0 \%$ after 9 years of type 2 diabetes (23). This duration is similar to that in our patients at the end of the prospective arm of the study, at which time 59.1 and $59.3 \%$ of $\mathrm{AC}$ and SE patients still had an $\mathrm{HbA}_{1 \mathrm{c}} \geq 7.0 \%$ for percentages of insulin users that were only 22.1 vs $14.3 \%$ respectively. These findings suggest that, as in the UKPDS, most of our patients would have needed insulin to achieve satisfactory glycaemic control.

The present study highlights some of the issues involved in managing patients with type 2 diabetes in a multicultural setting. The rate of progression through blood glucose-lowering therapies can differ significantly between ethnic groups. This includes the use of insulin, which will be required in most patients within a decade of diagnosis (23). Despite the introduction of insulin therapy, our data and those of others $(24,25)$ suggest that this may not improve glycaemic control. In some ethnic groups, notably the present SE patients, the early introduction of insulin is appropriate but a more aggressive dose titration is needed to meet recommended glycaemic targets.

\section{Acknowledgements}

We are grateful to the FDS staff for help with collecting and recording clinical information. We thank the Biochemistry Department at Fremantle Hospital and the Health Service for performing laboratory tests, and the Diabetic Education, Podiatry and Dietetic Departments for assistance with recruitment of patients. The Raine Foundation, University of Western Australia funded the FDS. R M C was the recipient of a National Health and Medical Research Council of Australia PhD Scholarship.

\section{References}

1 Australian Bureau of Statistics. National Health Survey 19891990: Diabetes, Australia. Catalogue No. 4371.0. Canberra: Commonwealth of Australia, 1991.

2 Welborn TA, Knuiman MW, Bartholomew HC \& Whittall DE. 1989-1990 National Health Survey: prevalence of self-reported diabetes in Australia. Medical Journal of Australia 1995163 129-132.

3 Bruce D, Davis WA, Cull CA \& Davis TME. Diabetes education and knowledge in patients with type 2 diabetes from the community: the Fremantle Diabetes Study. Journal of Diabetes and its Complications $20031782-89$

4 Phillips P, Wilson D, Beilby J, Taylor A, Rosenfeld E \& Hill W. Diabetes complications and risk factors in an Australian population. How well are they managed? International Journal of Epidemiology 199827 853-859.

5 Davis TME, Zimmett P, Davis WA, Bruce D, Fida S \& Mackay I. Autoantibodies to glutamic acid decarboxylase in diabetic patients from a multiethnic Australian community: the Fremantle Diabetes Study. Diabetic Medicine 200017 667-674.

6 Bruce DG, Davis WA \& Davis TME. Glycemic control in elderly subjects with type 2 diabetes mellitus in the Fremantle Diabetes Study. Journal of the American Geriatric Society $2000 \mathbf{4 8}$ 1449-1453.

7 Australian Bureau of Statistics. Perth - A Social Atlas Census 91. Canberra: Commonwealth of Australia, 1994.

8 Rowley MJ, Mackay IR, Chen OY, Knowles WJ \& Zimmet PZ. Antibodies to glutamic acid decarboxylase discriminate major types of diabetes mellitus. Diabetes 199241 548-551.

9 Law RHP, Rowley MJ, Mackay IR \& Corner BC. Expression in Saccharomyces cerevisiae of antigenically and enzymatically active recombinant glutamic acid decarboxylase. Journal of Biotechnology $19986157-68$.

10 Feldman EL, Stevens MJ, Thomas PK, Brown MB, Canal N \& Greene DA. A practical two-step quantitative clinical and electrophysiological assessment for the diagnosis and staging of diabetic neuropathy. Diabetes Care 199417 1281-1289.

11 Matthews DR, Hosker JP, Rudenski AS, Naylor BA, Treacher DF \& Turner RC. Homeostasis model assessment: insulin resistance and beta-cell function from fasting plasma glucose and insulin concentrations in man. Diabetologia $1985 \mathbf{2 8} 412-419$.

12 Muggeo M, Verlato G, Bonora E, Bressan F, Girotto S, Corbellini M, Gemma ML, Moghetti P, Zenere M, Cacciatori V, Zoppini G \& de Marco R. The Verona Diabetes Study: a population-based survey on known diabetes mellitus prevalence and 5-year all-cause mortality. Diabetologia $198538318-325$.

13 De Marco R, Locatelli F, Zopini G, Verlato G, Bonora E \& Muggeo M. Cause-specific mortality in type 2 diabetes. Diabetes Care 199922 756-761.

14 Garancini MP, Sergi A, Lazzari P \& Gallus G. Epidemiology of known diabetes in Lombardy, north Italy. Clinical characteristics and methodological aspects. Acta Diabetologia 199532 268-272.

15 Franciosi M, Pellegrini F, De Berardis G, Belfiglio M, Cavaliere D, Di Nardo B, Greenfield S, Kaplan SH, Sacco M, Tognoni G, Valentini M \& Nicolucci A. for the QuED Study Group The impact of blood glucose self-monitoring on metabolic control and quality of life in type 2 diabetic patients. Diabetes Care 200124 1870-1877.

16 Di Cianni G, Benzi L, Giannarelli R, Orsini P, Villani G, Ciccarone AM, Cecchetti P, Fedele O \& Navalesi R. A prevalence study of known diabetes mellitus in Tuscany assessed from pharmaceutical prescriptions and other independent sources. Acta Diabetologia $19943187-90$.

17 UKPDS Group. UK Prospective Diabetes Study 16: overview of 6 years' therapy in type 2 diabetes - a progressive disease. Diabetes $1995441249-1258$.

18 Robertson RP, Harmon JS, Tanaka Y, Sacchi G, Tran POT, Gleason CE \& Poitout V. Glucose toxicity of the $\beta$-cell: cellular and molecular mechanisms. In Diabetes Mellitus. A Fundamental and Clinical Text, edn 2, pp 125-132. Eds D Le Roith, S Taylor \& JM Olefsky. Philadelphia: Willliams \& Wilkins, 2000.

19 Fertig BJ, Simmons DA \& Martin DB. Therapy for diabetes. In Diabetes in America, edn 2, ch. 25, pp 519-540. Eds MI Harris, CC Cowie, MP Stern, EJ Boyko, GE Reiber \& PH Bennett. Bethesda, Maryland: National Diabetes Data Group of the National Institute of Diabetes and Digestive and Kidney Diseases, National Institutes of Health, 1995.

20 Harris MI, Klein R, Welborn TA \& Knuiman MW. Onset of NIDDM occurs at least $4-7$ years before clinical diagnosis. Diabetes Care $199215815-819$.

21 Davis TME, Stratton IM, Fox CJ \& Holman RR. UK Prospective Diabetes Study 22: Effect of age at diagnosis on diabetic tissue damage during the first 6 years of NIDDM. Diabetes Care 1997 20 1435-1441.

22 UKPDS Group, Intensive blood glucose control with sulphonylureas or insulin compared with conventional treatment and risk of complications in patients with type 2 diabetes (UKPDS 33). Lancet $1998352837-853$. 
23 Turner RC, Cull CA, Frighi V \& Holman RR. for the UK Prospective Diabetes Study Group Glycemic control with diet, sulfonylurea, metformin, or insulin in patients with type 2 diabetes mellitus. Journal of the American Medical Association 1999281 2005-2012.

24 Harris MI, Eastman RC, Cowie C, Flegal KM \& Eberhardt MS. Racial and ethnic differences in glycaemic control of adults with type 2 diabetes. Diabetes Care 199922 403-408.
25 Klein R, Klein BEK, Moss SE \& Cruickshanks KJ. The medical management of hyperglycaemia over a 10-year period in people with diabetes. Diabetes Care 199619 744-750.

Received 20 June 2004

Accepted 2 August 2004 